\title{
O ENSINO DE COMPETÊNCIAS LÓGICAS PARA A FORMAÇÃO CIDADÃ
}

\author{
Clarice Rosa Machado* \\ Marcio Paulo Cenci ${ }^{* *}$
}

\begin{abstract}
Resumo: Neste trabalho, pretende-se mostrar que o ensino da lógica desenvolve algumas competências que são essenciais para a formação de cidadãos. Para pensar essa problemática este trabalho foi estruturado em cinco tópicos, os quais são: O que se entende por formação cidadã; A Importância da Lógica para a Formação de Cidadãos; Aprendizagem por Competências: Quais Competências a Lógica pode ajudar a desenvolver?; Relato de Experiência de uma Aprendizagem baseada em Competências com a Lógica e a Análise dos dados coletados. O trabalho obteve sua metodologia pautada na pesquisa bibliográfica a partir da análise de materiais sobre o ensino de lógica; o conceito de competência; o conceito de formação cidadã e os aspectos do seu uso.
\end{abstract}

Palavras-chave: Aprendizagem; Ensino; Formação de Cidadãos; Lógica.

Resumen: Este trabajo busca demostrar cómo la enseñanza de la lógica desarrolla algunas competencias esenciales para la formación ciudadana. Para demostrar eso, este trabajo está estructurado en cinco puntos: lo que se entiende con formación ciudadana; la importancia de la lógica para la formación ciudadana; aprendizaje por competencias: ¿para cuáles competencias la lógica puede contribuir?; relato de experiencia de un aprendizaje basado en competencias como lógica y análisis de datos. La metodología de esta investigación es bibliográfica, a partir del análisis de materiales sobre la enseñanza de la lógica, el concepto de competencia, el concepto de formación ciudadana y los aspectos de su uso.

Palabras claves: Aprendizaje; Enseñanza; Capacitación Ciudadana; Lógica

\section{Introdução}

A formação de cidadãos pode ser desenvolvida a partir de competências obtidas com a aprendizagem da lógica. Nesse sentido, a lógica é importante para a formação de cidadãos, porque fornece instrumentos tanto para a análise de discursos quanto para a expressão de ideias. A importância da lógica para a formação de cidadãos está em auxiliá-los nas escolhas que irão tomar que afetam o resto da sociedade, na medida em que clarifica o pensamento para que as pessoas

\footnotetext{
" Licenciada em Filosofia, Universidade Franciscana (UFN). Mestranda em Humanidades e Linguagens da Universidade Franciscana (UFN).

E-mail: clarice.r.machado@gmail.com.

** Orientador. Dr. Professor de Filosofia da Universidade Franciscana (UFN).

E-mail:mpcenci@gmail.com.
}

não tomem decisões precipitadas ou confusas e consigam estabelecer diálogos respeitosos. Assim, entre as competências para a formação de cidadãos que podem ser fornecidas pelo ensino da lógica estão, por exemplo, o raciocínio crítico e a argumentação.

Para dar conta dessa problemática, este trabalho foi estruturado em cinco tópicos. O primeiro tópico foi desenvolvido a partir dos seguintes questionamentos: Há uma fundamentação segura e definitiva sobre o conceito de formação de cidadãos? $\mathrm{O}$ que se pensa quando se pronuncia formação de cidadãos? A formação de cidadãos é um dever exclusivo da escola? Quais as capacidades que uma pessoa precisa ter para ser considerado um cidadão? Deste modo, buscou-se resolver essas questões na medida em

MACHADO, Clarice Rosa; CENCI, Marcio Paulo. O ensino de competências lógicas para a formação cidadã. Revista Sul-Americana de Filosofia e Educação. Número 32/33: nov. 2019 - out. 2020, p. 30-46. DOI: https://doi.org/10.26512/resafe.v1i32/33.35110 
que se apresenta os aspectos do uso deste conceito. O segundo tem como questão central qual a importância da lógica para a formação de cidadãos? Assim, há um aprofundamento do estudo sobre a noção de formação de cidadãos, mas no âmbito do ensino da lógica. Além disso, se contextualiza brevemente a atual conjuntura da sociedade e então a necessidade de adquirir as ferramentas que o ensino da lógica oferece para se tornar um cidadão. Apresenta-se também que algumas das competências que podem ser desenvolvidas com o ensino da lógica que estão presentes na Base Nacional Comum Curricular (BRASIL, 2018).

No terceiro, buscou-se analisar quais as competências que o ensino da lógica desenvolve, bem como aquelas que estão previstas na BNCC. A partir da compreensão das competências oferecidas com o ensino da lógica mostrou-se algumas estratégias para desenvolvê-las. No quarto tópico faz-se um relato das aulas do Estágio Curricular Supervisionado III, as quais foram usadas especificamente para verificar o processo do desenvolvimento das competências lógicas no ensino de Filosofia no Ensino Médio. Nesse momento, aponta-se as estratégias e os conteúdos que foram trabalhados para realizar uma aprendizagem baseada em competências com a lógica. Para finalizar, no quinto tópico, realizou-se uma análise dos dados coletados, tendo como base dois gráficos dos resultados obtidos através das duas aplicações do questionário que aconteceram antes e depois das aulas de lógica apresentando as competências que foram desenvolvidas a partir de algumas atividades.
Esta pesquisa tem caráter exploratório para aprimorar as ideias acerca do ensino da lógica e está dividida em fundamentação teórica e em uma discussão de dados. Pretende-se coletar informações sobre conceitos lógicos tais como: contradição, consistência no ensino da lógica no âmbito do Ensino Médio como instrumento para desenvolver competências como a capacidade de raciocinar, de julgar os políticos sem o uso de falácias ad hominem, de pensar no bem de todos, para a formação de cidadãos. Nesta pesquisa, o ensino da lógica está baseado em (NUSSBAUM, 2015); (MURCHO, 2002; 2003). Nussbaum (2015) trata das contribuições das humanidades para a formação de cidadãos e defende a relevância da argumentação na medida em que esta proporciona aos estudantes a capacidade de formar suas próprias ideias e, consequentemente, de debater assuntos diversificados e de importância pública. Murcho (2003) apresenta os papéis da lógica na Filosofia os quais são: clarificar o pensamento e ajudar a evitar erros de raciocínio. Esses papéis são necessários para compreensão dos argumentos utilizados pelos filósofos, o que colabora para a formação dos estudantes.

Murcho (2002) retrata pontos valiosos da história da Filosofia, evidenciando os fatores como a formação que tiveram nas faculdades que se torna irrelevante para a prática docente. Alguns relatam que foram ensinados a comentar e não a pensar os problemas filosóficos, assim, apenas reproduzem as fórmulas de pensadores, a massificação do ensino no qual tiveram uma formação inadequada não sendo capazes de explicar ou pensar uma determinada situação. Um dos casos de desmotivação dos alunos é a inter- 
net, as mídias que acabam sendo mais atrativas para os alunos, uma vez que tem resultado mais imediato do que estudar os textos antigos dos filósofos. Além disso, expõem algumas ferramentas que os alunos precisam adquirir para pensar criticamente as teorias $e$ os problemas filosóficos, assim como, para refletir, questionar e tentar resolver os problemas de suas vidas. Outras obras de grande valor sobre os assuntos mencionados anteriormente, que contribuíram para a pesquisa foram: (ROCHA, 2015), (VELASCO, 2016), (HECK, 2017).

Como fundamentação para trabalhar com o conceito de competência a pesquisa está apoiada em ZABALA e ARNAU (2010). Segundo eles, esse conceito ganha espaço no debate sobre a educação devido a necessidade de superar o ensino, em que o professor é considerado o detentor do conhecimento enquanto o aluno é o receptor, que até o momento é predominante. $\mathrm{O}$ ensino por competência torna-se eficiente para que esses conteúdos sejam aplicados na vida dos alunos e que estes por sua vez tenham uma formação integral.

Após a descrição da metodologia de fundamentação teórica do trabalho, passouse a discussão dos dados acerca das competências lógicas básicas que os estudantes do Ensino Médio dispunham. Tendo em vista esse propósito, produziu-se um questionário como modelo de experimentação o qual visava a mapear a interpretação de texto dos alunos e sua capacidade de mobilizar noções como contradição e consistência do discurso. Esse questionário foi elaborado a partir de um diálogo composto por dez falas entre duas meninas que se dirigiam para a sala de aula após bater o sinal da escola. Apoiado no diálogo entre as meninas, montou-se o questionário com seis questões que abarcam algumas alternativas. Para recolher os dados da experiência foram contabilizados trinta $e$ cinco questionários, isso equivale ao número total de estudantes que participaram da pesquisa.

Os sujeitos da pesquisa foram estudantes do segundo ano do Ensino Médio de uma escola estadual da cidade de Santa Maria, com os quais realizou-se o Estágio Curricular Supervisionado III de regência de Filosofia. O número total de horas aulas contabilizadas durante o estágio de conteúdos e atividades efetivas do ensino da lógica foram sete horas aulas. A turma foi selecionada tendo em vista o ano em que se trabalha o conteúdo de lógica, de acordo com o plano de ensino da disciplina de Filosofia vigente nessa escola. Na ocasião da aplicação do questionário, não houve identificação dos alunos para salvaguardar a dignidade, os direitos, a segurança e o bem-estar dos sujeitos da pesquisa. Cabe ressaltar que não foi preciso recorrer ao Comitê de Ética, pois o questionário era uma das atividades que estava prevista no plano de ensino da disciplina.

A aplicação do instrumento da coleta de dados foi executada em duas etapas, ambas no ano de 2017 durante o estágio de regência III. A primeira efetuou-se no mês de março, com o intuito de verificar os conhecimentos advindos do senso comum que os alunos possuíam. Como a intenção era comparar as informações apanhadas nas duas etapas, os resultados foram apresentados apenas para o professor titular de Filoso- 
fia da turma e para a supervisora do estágio. $\mathrm{Na}$ segunda e última etapa que ocorreu no mês de junho, o questionário foi aplicado para investigar se houve alguma mudança nas respostas dos estudantes alicerçada nas aulas de lógica ministrada pelo estagiário. $\mathrm{O}$ objetivo do experimento foi utilizá-lo como um parâmetro de comparação entre as duas aplicações do questionário, e assim de averiguar se com as aulas da lógica, os alunos obtiveram maior conhecimento sobre as noções de contradição, consistência do discurso e, também, verificar sua capacidade interpretativa. Para a finalização do experimento, no último dia de aula, o questionário foi corrigido junto com a turma para mostrar os pontos em que erraram e explicar a razão da resposta não estar certa. A correção conjunta tinha por finalidade fazer com que os estudantes compreendessem que o ensino da lógica consiste em um elemento indispensável para o aprimoramento da racionalidade humana enquanto estratégia para resolver problemas cotidianos. Nesse sentido, no desenrolar do estágio, tinha-se a pretensão de desenvolver algumas competências tais como: usar a racionalidade lógica e criativa para contribuir na formação integral do aluno e, ao mesmo tempo, oferecer condições para o desenvolvimento da consciência crítica com o intuito de que este possa defender suas ideias com argumentos mais consistentes em todos os âmbitos da vida.

\section{O que se entende por formação cidadã}

A formação cidadã é um assunto importante para a atualidade, porém carrega uma carência de fundamentação segura $e$ definitiva. Como há a necessidade de pensar melhor sobre esse conceito, com o apoio de BIESTA (2013), DALBOSCO (2013) e NUSSBAUM (2015), pretende-se tencioná-lo a fim de apresentar, ao menos, aspectos de seu uso. Quando se pensa em formação de cidadãos, automaticamente, remete-se à educação, haja vista que a educação é sempre uma intervenção na vida de alguém. Biesta (2013, p. 156) sugere que "a responsabilidade educacional não é apenas uma responsabilidade pela vinda ao mundo de seres únicos e singulares; é também uma responsabilidade por um mundo de pluralidade e diferença". A responsabilidade educacional está relacionada com a responsabilidade pela 'humanidade do ser humano', ou seja, pela unicidade e singularidade de cada ser humano. Contudo, formar cidadãos não é um dever somente da escola, mas da família e de outras instituições sociais. $\mathrm{O}$ primeiro contato social que a criança tem é no seio familiar com sua mãe, seu pai, irmãos, tios, $e$ assim inicia sua convivência com outras pessoas. Disso, fica evidente a responsabilidade e importância da família em educar o sujeito a conviver bem com outras pessoas.

Em conformidade com Nussbaum (2015), antes de realizar qualquer planejamento pedagógico na escola, é necessário conhecer os problemas que os estudantes têm de enfrentar para que tenham uma formação cidadã. Nas democracias emergentes é importante "[...] as escolas tenham um papel central a desempenhar na formação de cidadãos democráticos e na criação de uma cultura democrática" (BIESTA, 2013, p.157). Nussbaum (2015) ainda chama atenção para uma formação que irá transformar a vida do estudante, no sentido de 
fazê-lo pensar não somente no que está em sua volta ou onde suas vistas alcançam, mas também, nos acontecimentos de todo o mundo. A educação que forma cidadãos precisa desenvolver nos seus alunos a capacidade de ver o mundo do ponto de visto do outro, ou seja, de tal maneira que eles consigam se colocar no lugar do outro de modo a reagir compassivamente com a pessoa em determinada situação. Ensinar que a fragilidade humana como, por exemplo, o medo, a ansiedade ou, precisar do outro, não significa que eles sejam fracos ou que é para terem vergonha, mas que são sentimentos que dão a possibilidade de uma integração, uma cooperação entre as partes (NUSSBAUM, 2015). Mostrar que se tem fragilidades é o ato mais corajoso na atualidade, uma vez que se tem uma errônea percepção de que quanto mais esconder os sentimentos, mais corajoso se é, e assim, as pessoas se distanciam umas das outras cada vez mais.

Nesse sentido, Dalbosco (2015) defende que para os estudantes exercerem suas capacidades críticas e imaginativas na sua vida, e assim, pensar no outro com empatia e refletir sobre as suas atitudes, eles precisam de uma educação que formem cidadãos. "Hoje a questão mais importante é como podemos reagir responsavelmente ao que $e$ a quem é o outro, e como podemos viver pacificamente com o que ou quem é o outro" (BIESTA, 2013, p. 31). Uma pessoa que possui uma formação cidadã estará apta para solucionar qualquer problema tanto no campo individual, social quanto no político. Esse indivíduo terá capacidade de decidir $e$ pensar por si mesmo, participará ativamente da vida democrática, em questões sobre a educação e os governantes, estará bem informado sobre tudo o que acontece tanto no seu país quanto nos outros (BIESTA, 2013). Será um cidadão que buscará melhorias para todos, argumentando, posicionando-se como cidadão em uma democracia.

\section{A importância da Lógica para a formação de cidadãos}

Há artigos que dissertam sobre a importância do ensino da lógica para o desenvolvimento de algumas habilidades necessárias para os estudantes do Ensino Médio, tais como: (CAMELO, 2014), (HECK, 2017), (PORTO, 2012). Essas habilidades são a capacidade de interpretação de texto nos mais variados assuntos, o desenvolvimento do raciocínio lógico, o desenvolvimento da argumentação, a capacidade de reconhecer falácias, entre outras. Mas essas habilidades não poderiam ser ensinadas nas disciplinas de Português ou de Matemática? O que essas habilidades ensinadas na Filosofia têm de diferente do que é ensinado nas outras áreas? Para não cair nesse reducionismo encontrado em muitos textos que falam sobre esse assunto, o que se busca neste trabalho é analisar as competências específicas do ensino da lógica para a formação de cidadãos, sem descartar, contudo, que essas mesmas habilidades possam ser ensinadas por outras disciplinas do currículo escolar.

Conforme Nussbaum (2015), o mundo atual precisa de cooperação entre as pessoas e os países para que ambos se apoiem quando for preciso independente de se conhecerem ou não. Deste modo, tudo o que acontece em outros países acaba nos afetan- 
do direta ou indiretamente. O que se concebe quando se fala de formação de cidadão? Ou, como é possível falar da ausência de cidadãos? E a questão central deste capítulo, qual a importância da lógica para a formação de cidadãos? Nesta seção, objetiva-se a responder essas dúvidas acerca da formação de cidadãos, contudo, sem perder o foco de que a formação da qual se fala no trabalho, acontece no âmbito do ensino da lógica.

A sociedade se desenvolveu a partir da necessidade de confeccionar os materiais para sua subsistência os quais não eram fornecidos pela natureza de forma espontânea, assim, o homem passou a produzir as utilidades que precisava para sua existência, tendo como consequência, um desenvolvimento econômico e social que assegurou espaço, diretos e deveres aos cidadãos com o passar dos anos. Poder-se-ia elencar cada um dos direitos e deveres dos cidadãos, porém o propósito não é esse, então apontarse-á alguns para ilustrar o peso que a palavra cidadão carrega. Entre eles o direito à igualdade, à liberdade, à segurança, à moradia, liberdade de manifestação do pensamento, educação e o direito ao voto. Assim, o humano enquanto cidadão terá que proteger os seus interesses sociais exercendo os seus direitos e deveres.

De acordo com Nussbaum (2015), considera-se que, a educação tem como centro o desenvolvimento da formação de cidadãos, nesse sentido, ela oferece condições e ferramentas para que este lute pela democracia exercendo seus direitos e cumprindo com os seus deveres, assim, a educação possibilita que o aluno participe do mundo ativamente. Desta forma, o estudante terá uma visão de homem comprometido com o mundo que o cerca, isto é, ele estará apto a fazer escolhas corretas no que diz respeito à temas de importância nacional e internacional. Nussbaum (2015) defende a importância das humanidades para a educação de cidadãos competentes, informados, democráticos, independentes e responsáveis ao mesmo tempo em que proporciona uma reflexão acerca do caminho que a educação está trilhando com a desvalorização das artes e das humanidades em prol de uma educação voltada para a técnica e para o lucro.

Com uma educação que possui como essência as humanidades, os estudantes aprendem junto ao conteúdo, a terem raciocínio crítico e a desenvolverem a empatia. Assim, Nussbaum $(2015$, p. 4) defende que com o estudo das humanidades se produz "cidadãos íntegros que possam pensar por si próprios, criticar a tradição e entender o significado dos sofrimentos $e$ das realizações dos outros". A autora defende ser esse o único caminho para garantir o futuro da democracia, isto é, a existência de pessoas que se preocupam com o bem-estar dos outros, que não sejam egocêntricos, e que não se deixem enganar por argumentos falaciosos de algumas "autoridades".

As crianças que não têm um ensino que invista nas humanidades são ensinadas a buscar apenas o lucro e podem se tornar pessoas que têm suas relações baseadas exclusivamente em interesses, as quais estariam sempre procurando mais poder, mesmo que para realizar seus projetos sejam capazes atrapalhar ou causar problemas na vida de outros seres humanos. 
[...] parece que estamos nos esquecendo da alma, do que significa para a mente abrir a alma e ligar a pessoa com o mundo de modo rico, sutil $e$ complexo; do que significa aproximar-se de outra pessoa como uma alma, em vez de fazê-lo como um simples instrumento útil ou um obstáculo aos seus próprios projetos; do que significa conversar, com alguém que possui alma, com outra pessoa que consideramos igualmente profunda e complexa (NUSSBAUM, 2015, p.7).

Essa incapacidade de pensar e expressar as ideias leva as pessoas a realizarem atos maus que acabam atingindo pessoas inocentes sem nenhum motivo, ou seja, a falta de entendimento mútuo pode levar a situações de conflito, guerras e violência. $\mathrm{E}$, por outro lado, se as pessoas forem estimuladas desde a escola a buscarem o entendimento mútuo essas situações poderiam ser evitadas. Deste modo, Velasco (2016) defende que a lógica se torna importante para a formação de cidadãos, pois fornece instrumentos para a análise de discursos, uma vez que essa é indispensável para expressar as ideias de forma clara e compreender as ideias dos outros.

Para usufruir de um ensino que seja voltado para reflexões acerca dos acontecimentos do mundo com pessoas que realizam ações para além do interesse próprio e que se preocupam com a manutenção das instituições democráticas, é preciso olhar com seriedade para o ensino da lógica. Conforme Nussbaum (2015, p. 26), entre as competências necessárias para uma democracia está a "capacidade de raciocinar adequadamente a respeito de temas políticos que afetem a nação, de examinar, refletir, argumentar e de- bater, não se submetendo nem à tradição nem à autoridade". Entre as competências para a formação de cidadãos que podem ser fornecidas pelo ensino da lógica estão, por exemplo, o raciocínio crítico e a argumentação. Essas competências estão presentes na Base Nacional Comum Curricular e serão mencionadas no próximo tópico.

Preocupada com a educação atual, Nussbaum fala sobre a necessidade de algumas competências que estão ligadas às humanidades, nos currículos escolares, as quais se pode chamar de "espírito das humanidades", e essas são: "a busca do raciocínio crítico, das ideias ousadas, da compreensão empática das diferentes experiências humanas e da compreensão da complexidade em que vivemos" (2015, p. 8). Argumenta-se que no caso de algumas dessas competências, o ensino da lógica pode auxiliar no seu desenvolvimento (mas será analisado mais detalhadamente no próximo ponto). Segundo Nussbaum, as competências que precisam ser desenvolvidas para a formação de cidadãos são: i) capacidade de raciocinar, nesta também está presente algumas habilidades como análise, reflexão, argumentação; ii) capacidade de reconhecer o outro como uma pessoa que possui os mesmos direitos que eu independente de sua etnia, religião, gênero, orientação sexual e país de origem; iii) capacidade de sentir empatia e respeito pelo outro, isto é, se colocar no lugar do outro e ter uma predisposição para ajudá-lo, porém não é ter compaixão somente por quem se conhece, mas também pelos desconhecidos; iv) capacidade de julgar os políticos, sem o uso de falácias ad hominem ou qualquer outra que visa a prejudicar o outro sem fundamentação ou tendo como base de 
julgamento os sentimentos pessoais; v) capacidade de pensar no bem de todos, não somente no grupo, cidade ou país ao qual pertence, mas que o bem seja ampliado para fora do local em que reside ${ }^{3}$.

Assim, pode-se dizer que a lógica é importante para a formação de cidadãos, porque se faz presente nas relações dos humanos com outros e com o mundo que o cerca, na medida em que o humano reflete, analisa, e questiona sobre os acontecimentos que o rodeiam, argumentando acerca dos mais variados assuntos e realizando julgamentos fundamentados em evidências sólidas e verdadeiras. E, para realizar essas habilidades é preciso pensar de forma coerente, e esta é outra competência necessária para formação de cidadãos. As universidades acreditam que as humanidades e na relevância da argumentação, pois elas proporcionam a possibilidade de debater sobre os mais diversos assuntos, tanto pessoais quanto de ordem pública. Sócrates foi o filósofo que mais defendeu até sua morte a importância da argumentação. Para ele a única coisa que vale é a natureza da argumentação, independente de classe, bens materiais e status social que a pessoa possua, todos somos iguais diante da argumentação.

Todo mundo precisa ser examinado, $e$ todos são iguais diante da argumentação. Essa postura crítica expõe a estrutura da posição de cada um, revelando, durante o processo, hipóteses compartilhadas e pontos de intersecção que podem ajudar os concidadãos a avançar para uma con-

\footnotetext{
${ }^{3}$ Essas competências podem ser conferidas na obra Sem Fins Lucrativos (2015, p. 26). Essas foram algumas das competências que Nussbaum esboça em sua obra, mas que aqui foram resumidas.
}

clusão comum (NUSSBAUM, 2015, p. 51).

Nota-se que as humanidades são necessárias para uma vida pautada em empatia, solidariedade, reciprocidade, respeito, autonomia. Tudo o que acontece em um país acaba afetando os outros, direta ou indiretamente. E a educação, por sua vez, deve auxiliar os alunos a desenvolverem essas competências para que não sejam pessoas egoístas e que baseiam suas relações em interesse. As pessoas se tornam responsáveis pelos seus atos e assim, passam a refletir sobre as consequências de suas escolhas.

A importância da lógica para a formação de cidadãos é auxiliá-los nas escolhas que irão tomar que afetam o resto da sociedade. E para clarear o pensamento para que as pessoas não tomem decisões precipitadas ou confusas e consigam estabelecer diálogos respeitosos, na medida em que levam em consideração as opiniões contrárias. Cidadãos instruídos conseguem perceber as diferenças e buscar resolver os problemas tanto deles quanto dos outros, são pessoas que prezam pela felicidade de todos os seres vivos. Uma vez que precisamos nos manter informados sobre as decisões dos governantes de nosso país, e escolher quem nos representa na vida pública, perceber que as humanidades estão intimamente ligadas às competências lógicas é conveniente para compreender o quão necessário são o estudo delas para o futuro dos seres humanos.

\section{Aprendizagem por competências: quais competências a Lógica pode ajudar a desen- volver?}


Para entender o desenvolvimento deste tópico é significativo saber que no texto interpreta-se habilidades e competências como sendo distintas. Concebe-se "habilidade" como a capacidade que uma pessoa adquire para desempenhar uma determinada função, ou seja, é apreendida por meio de um treinamento (ZABALA; ARNAU, 2010). No que se refere a "competência", é entendida como a união de todas essas habilidades aprendidas, devendo identificar o que qualquer sujeito precisa para solucionar os problemas aos quais será exposto ao longo da vida (ZABALA; ARNAU, 2010). Este esclarecimento sobre o que se entende por habilidade e por competência é importante para compreender o que é uma aprendizagem por competência, antes de adentrar nas competências da lógica. Embora o conceito de competência tenha sua gênese no campo empresarial (DUTRA; FLEURY; RUAS, 2008), ela é aplicada ao campo educacional, com o objetivo de solucionar a limitação da educação tradicional (ZABALA; ARNAU, 2010). Como a educação tradicional enfatiza o ensino de conteúdo, essa abordagem enfatiza a aprendizagem por meio de competências.

O uso do termo competência é uma consequência da necessidade de superar um ensino que, na maioria dos casos, reduziu-se a uma aprendizagem cujo método consiste em memorização, isto é, decorar conhecimentos, fato que acarreta na dificuldade para que os conhecimentos possam ser aplicados na vida real (ZABALA; ARNAU, 2010, p. 17).

É importante entender a expressão "ser aplicado na vida real". Os autores tomam isso como óbvio, mas não é evidente.
Podemos interpretar essa expressão em dois modos: um modo é a interpretação voltada para o mercado de trabalho, uma aprendizagem para o vestibular. Outro modo, é justamente aquele tipo de conhecimento que diz respeito a aspectos mais amplos da vida que não necessariamente tenha uma importância para o mercado de trabalho (NUSSBAUM, 2015; ORDINE, 2016). Contudo, considera-se importante que o aluno tenha uma formação que desenvolva suas capacidades, não apenas para o meio escolar, mas para todos os âmbitos da vida. Deste modo, mostra-se que o termo competência tem sua gênese com o intuito de colocar em questão a importância dos conhecimentos adquiridos na escola e sua aplicação na realidade para além das exigências estritas do mercado de trabalho.

A competência, no âmbito da educação escolar, deve identificar o que qualquer pessoa necessita para responder aos problemas aos quais será exposta ao longo da vida. Portanto, a competência consistirá na intervenção eficaz nos diferentes âmbitos da vida por meio de ações nas quais se mobilizam, ao mesmo tempo e de maneira inter-relacionada, componentes atitudinais, procedimentais $e$ conceituais (ZABALA; ARNAU, 2010, p. 10).

Para ensinar competências é preciso usar métodos diferentes de ensino e que sejam consistentes para responder aos obstáculos e problemas que surgirem no cotidiano dos educandos. É um processo em que o aluno precisa exercitar os conhecimentos adquiridos com conflitos que ocorrem na vida extraescolar. Uma construção em todos os âmbitos do ser humano, pessoal, social, interpessoal e profissional. 
A Base Nacional Comum Curricular (BRASIL, 2018) é construída a partir algumas competências gerais que os estudantes precisam adquirir no decorrer de toda a educação básica, bem como competências específicas para cada disciplina do currículo. As competências de exercitar a curiosidade intelectual; valorizar a diversidade de saberes $e$ vivências culturais $e$ a argumentar são algumas que estão inseridas na $\mathrm{BNCC}^{4}$, que podem ser desenvolvidas com o ensino da lógica. O exercício da curiosidade intelectual inclui a investigação, a reflexão, análise crítica e a elaboração de hipóteses para resolver problemas com base nos conhecimentos adquiridos pelas diferentes áreas do currículo escolar. A valorização da diversidade se ocorre quando os estudantes se apropriam dos conhecimentos e experiências que lhes possibilitem entender o mundo com liberdade e autonomia. A competência da argumentação acontece quando os estudantes se posicionam de forma ética com relação aos outros e ao mundo por meio de informações e dados confiáveis que lhes permitem defender suas ideias e decisões respeitando os direitos humanos.

Favaretto (2015) defende a ideia de ensinar aos estudantes os exercícios que potencializam o pensamento. "Aprender a detectar pressupostos, a reconhecer as funções mais frequentes e mesmo gerais do funcionamento dos discursos, a reconstruir argumentos a partir da leitura, confrontar teses ou posições, emitir juízos próprios e funda-

\footnotetext{
${ }^{4}$ Conferir página 18-19 da Base Nacional Comum Curricular para verificar as outras competências gerais. Disponível em:

http://basenacionalcomum.mec.gov.br/images/BNCC publicacao.pdf. Acesso em: 16 mai. 2018.
}

mentados, são exercícios que podem desatar a potência do pensamento" (2015, p. 16). Podemos notar que embora Favaretto tenha optado por dizer exercícios, poder-se-ia dizer que são competências que potencializam o pensamento. A capacidade de refletir, de analisar, resolver problemas, investigar $e$ argumentar são algumas competências que o ensino de lógica permite que o estudante desenvolva, e essas influenciam nas suas relações nos diversos âmbitos da vida. Diante disso, abordarei quais ferramentas da lógica poderiam contribuir para que o aluno consiga desenvolver essas três competências, citadas anteriormente, que estão presentes na BNCC.

No que concerne às competências referidas na BNCC, elas podem ser trabalhadas, por exemplo, com a obras que mobilizem a ludicidade, como a obra Alice no País dos Enigmas (SMULLYAN, 2003). Posto que nesse livro há vários enigmas e problemas que necessitam de uma análise cautelosa para chegar a uma resposta. Os enigmas são escritos em diálogos que, por sua vez, exigem atenção no momento da investigação e na elaboração das hipóteses para resolver os problemas. Portanto, esse material ajuda a desenvolver competências importantes para a vida dos estudantes nos diversos campos da vida. A Secretaria de Educação Básica reconhece que "trata-se da criativida$\mathrm{de}$, da curiosidade, da capacidade de pensar múltiplas alternativas para a solução de um problema, ou seja, do desenvolvimento do pensamento crítico, da capacidade de trabalhar em equipe, da disposição para procurar $e$ aceitar críticas" (2006, p.30). Assim, tornase de grande relevância que eles adquiram essas competências, pois assim conseguirão 
se preparar para distinguir o que é enganoso do que é correto, levantando hipóteses e resolvendo os problemas que surgirem ao longo de suas vidas.

A capacidade crítica é um exercício em que nos distanciamos do objeto para realizar um exame detalhado das consequências e da causa desse. Segundo Nussbaum, "o raciocínio crítico deve ser introduzido no ensino de muitos tipos de classe, no momento em que os alunos aprendem a investigar, a avaliar a prova, a escrever ensaios com uma argumentação bem estruturada e a analisar os argumentos apresentados a eles em outros textos" (2015, p. 55). Ensinar os alunos a colocar em prática, na medida em que coloca dúvidas naquilo que lhe é apresentado e em suas crenças. Mas, é de grande relevância entender que é uma crítica fundamentada em um jogo de dar e pedir razões para essas dúvidas. Deste modo a:

"Consciência crítica", no final das
contas, pode ser um dos nomes de
uma habilidade típica dos seres hu-
manos. Ela é, de um lado, uma vir-
tude, fruto de aprendizado; de outro,
todo ser humano a possui em grau
mínimo, ao menos, pelo simples fato
que somos essencialmente depen-
dentes de informações para orientar
as decisões quotidianas (ROCHA,
2015 , p. 61).

A competência argumentativa pode ser desenvolvida com o estudo das falácias e do silogismo as quais são tipos de argumentos. Com o estudo de argumentos, podemos capacitar os alunos para defender suas ideias e a aceitar hipóteses contrárias, a estabelecer diálogos civilizados, no sentido de não ofender o outro. Além disso, uma pessoa com essa habilidade consegue identificar discursos falaciosos que são um tipo de argumento enganoso, mas muito persuasivo, que buscam apelar para as emoções de seus ouvintes.

As noções de argumento válido $e$ não válido, de prova $e$ de consequência lógica, de bons fundamentos para o pensamento e para a ação, e de consistência são tais que qualquer pessoa instruída deveria aprender a empregar, não apenas com familiaridade, mas com um certo grau de competência (GEACH, 2013, p.9).

Sofiste (2007) considera que há uma lógica da aprendizagem, na qual a finalidade do ensino não é somente a aquisição de saberes, mas sobretudo do desenvolvimento das competências formais de problematizar, argumentar, conceituar, que são essenciais à vida numa sociedade democrática. Podemos notar, que a preocupação com a lógica vem ganhando espaço nos escritos de muitos autores, devido ao desenvolvimento de competências cidadãs de importante impacto na sociedade.

\section{Relato de experiência de uma aprendizagem baseada em competências com a Lógica}

Neste subcapítulo será abordado apenas algumas das aulas do Estágio Curricular Supervisionado III, as quais foram usadas especificamente para verificar o processo do desenvolvimento das competências lógicas no ensino de Filosofia no Ensino Médio. Nesse sentido, será feito um relato evidenciando os objetivos da aula, as atividades e as competências. Assim, com isso pretende-se capacitar os alunos com competências úteis nas suas vivências diárias e enfatizar a neces- 
sidade do ensino da lógica para a formação de cidadãos.

Na primeira aula foi aplicado o questionário para examinar o que os alunos sabiam sobre o tema, a partir de suas indagações do cotidiano iniciou-se o conteúdo. Essa primeira aula tinha como objetivo verificar os conhecimentos que os alunos possuíam sobre o tema, refletir sobre a importância da lógica e mostrar que ela está presente no dia a dia e apresentar a definição de lógica $e$ suas divisões. As competências desta aula foram: investigação, reflexão e problematização. Na segunda aula, os objetivos foram expor as regras e a estrutura da argumentação para exercitar, aperfeiçoar o raciocínio $e$ aprender a diferença entre um argumento verdadeiro e válido de um argumento verdadeiro e inválido. Com alguns problemas que estão presentes no cotidiano dos alunos, como, por exemplo, as contradições em anúncios publicitários, frases extraídas de outras mídias e diálogos que foram estabelecidos pelos próprios alunos sobre acontecimentos escolares, como por exemplo, a escolha do líder da turma. As competências trabalhadas nessa aula foram: a argumentação e o raciocínio crítico.

A competência de identificar falsos argumentos e conseguir argumentar corretamente são necessárias para uma sociedade democrática. Desse modo, os alunos conseguiram estabelecer diálogos, e entrar em um acordo comum da turma a partir de um debate racional (WALTON, 2006). A partir de relatos dos próprios estudantes, notou-se um avanço nas competências de argumentação, pois antes os alunos afirmavam que "partiam" para a ofensa quando os colegas não concordavam com suas opiniões. Nussbaum afirma que "a capacidade refinada de raciocinar e refletir criticamente é crucial para manter as democracias vivas e bem vigilantes" $(2015,11)$.

Para ser mais bem compreendido a estrutura de um argumento e a importância deste no dia-a-dia, foram utilizadas mais duas aulas para o tratamento do conteúdo. $\mathrm{Na}$ terceira, os alunos realizaram exercícios sobre a estrutura do argumento, acerca da qualidade (afirmativa ou negativa) e da quantidade (universal ou particular) das proposições, a produção de argumentos a partir dessa estrutura e a identificação de premissas e da conclusão em alguns trechos selecionados. Nessa aula, tinha-se o intuito de verificar os conhecimentos e oferecer esclarecimento sobre a aula anterior. A turma foi organizada em grupos, na quarta aula, para debater argumentativamente alguns assuntos como por exemplo, o aborto, a situação política do país, a partir da leitura de alguns textos que a professora disponibilizou.

Na quinta aula foi apresentado alguns exemplos de tipos de falácias para auxiliar os estudantes a perceberem as diferenças existentes entre bons argumentos e argumentos falaciosos; e desenvolver nos alunos a habilidade crítica e interpretativa para evitar enganações. A atividade proposta foi que os alunos se juntassem em grupos de cinco alunos e desenvolvessem uma propaganda usando algumas falácias que eles identificaram nos discursos publicitários. A competência do raciocínio crítico e interpretativo necessários para reconhecer falácias. "A capacidade de detectar falácia é uma das coisas 
que tornam a vida democrática tolerável" (NUSSBAUM, 2015, p. 75).

Os alunos, na sexta aula, foram levados ao laboratório de informática para pesquisar outros tipos de falácias com o intuito de adquirir mais conhecimento sobre as demais e, buscar outras falácias que os ajudariam na sua propaganda que seria apresentada em forma de seminário para os outros colegas. A sétima aula, os alunos trocaram os conhecimentos sobre as falácias que utilizaram nas suas propagandas, explicando o motivo de ter escolhido tal falácia e comentando como foi a experiência de trabalhar dessa forma. Alguns alunos que eram repetentes, afirmaram que o conteúdo de lógica ficou mais acessivel da forma como foi trabalhado naquele ano, pois "a responsabilidade que nos foi dada para montar a propaganda e o seminário fez com que nos sentíssemos parte da aula. Não foi só chegar e jogar o conteúdo em cima do cara". Nesse sentido, a partir dos conhecimentos adquiridos, posteriormente, ao estudar lógica, a finalidade dessa aula foi a de munir os alunos de instrumentos que potencializam a capacidade de argumentar.

\section{Análise dos dados coletados}

É importante salientar que das treze aulas do Estágio Curricular Supervisionado III, apenas setes foram de conteúdo efetivo sobre lógica com exercícios, seminários $e$ debates, as outras seis aulas foram de provas e outras atividades que estavam no cronograma da escola para o primeiro trimestre de 2017. Além disso, na primeira aplicação do questionário a turma continha 22 alunos, mas no último dia de aula estavam 13 alu- nos. Com o intuito de realizar uma análise dos dados coletados, optou-se por selecionar apenas dois gráficos que representassem nitidamente as diferenças entre as duas aplicações do questionário, antes e depois das aulas de lógica.

Segue-se o diálogo apresentado:

"Cena 1) Bateu o sinal e Ana e Carla estão se dirigindo para a sala de aula.

Ana: Carla, me espera um pouco, pois eu preciso ir ao banheiro.

Carla: Mas, Ana, por que tu não foste antes? Ana: Agora é que me deu vontade.

Carla: Agora que bateu o sinal?

Ana: Sim, pois antes eu estava mexendo no celular e fazendo meu lanche.

Carla: Tu deverias ir ao banheiro durante o recreio, pois agora é o horário da aula!

Ana: $O$ professor nem vai perceber que a gente vai chegar atrasada.

Carla: Claro que ele vai ver! Mas, mesmo que ele não perceba, tu achas correto ir na hora que bate o sinal para voltar para a aula?

Ana: Eu acho errado, mas eu acho certo eu poder ir agora. Minha mãe sempre diz para não ficar muito tempo sem ir ao banheiro.

Carla: Tu não tens jeito mesmo, Ana. Tu sempre achas uma desculpa para fazer o que quer!"

Para desenvolver a competência do raciocínio crítico na questão 1 , foram realizadas atividades que deixassem os alunos curiosos, estimulando-os com exercícios que desafiavam a mente. Ou com conversas sobre um filme que eles assistiram no fim de semana, alguma postagem nas redes sociais, questionando as próprias crenças $e$ analisando as situações. Exercícios de encadear os juízos para que se possa acreditar em na 
conclusão, tal como, "o ouro conduz eletricidade"; "a prata conduz eletricidade", "logo, todos os metais conduzem eletricidade". Esse exemplo, foi apresentado de forma organizada, mas na aula, foi entregue desorganizado para que os alunos exercitarem o raciocínio.

Além disso, as atividades de questões sobre proposições ajudaram no desenvolvimento dessa competência. Dada a proposição "Todas as provas são chatas", por que é particular? Outra atividade foi distinguir $e$ justificar os argumentos dedutivos $e$ indutivos. No seguinte trecho: "Um hortelão que cultiva sua própria horta, com suas próprias mãos, reúne em sua própria pessoa três diferentes caracteres: de proprietário rural, de agricultor e de trabalhador rural. Seu produto, portanto, deveria pagar-lhe a renda do primeiro, o lucro do segundo e o salário do terceiro", os alunos precisaram identificar que este é um argumento dedutivo, porque não recorre à experiência para estabelecer qual é o caso. Mas tenta provar o caso de que o produto do hortelão deveria pagar a sua renda.

A questão 1 do questionário, dava o comando para completar a frase:

"Questão 1: Ana acredita que:

a) Não é errado esperar bater o sinal para ir ao banheiro.

b) É errado esperar bater o sinal para ir ao banheiro."
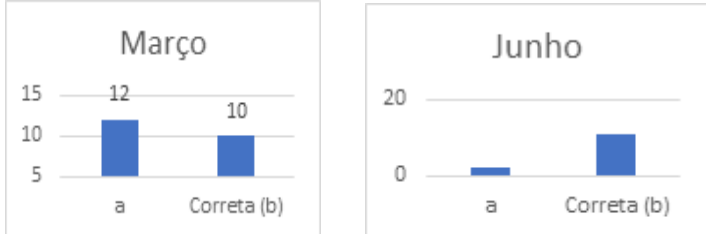

Figura 1: Gráfico das respostas da questão 1 do questionário.
A resposta correta é a "b", pois Ana diz que acha errado esperar bater o sinal, mas ela quer que essa regra não se aplique ao caso dela. Se pensar no que acontece ao longo do dia, a atitude de Ana representa algumas situações, em que se cobra do outro quando este faz alguma ação considerada errada, mas quando é ao contrário se quer algumas exceções. A partir da comparação da primeira aplicação do questionário realizada no mês de março e da segunda que aconteceu no mês de junho nota-se o avanço da aprendizagem dos alunos. No gráfico do mês de março, a quantidade de alunos que marcaram a alternativa 'a) Não é errado esperar bater o sinal para ir ao banheiro' é maior do que aqueles alunos que marcaram a segunda opção. No mês de junho a alternativa correta 'b) É errado esperar bater o sinal para ir ao banheiro' foi a mais marcada. Deste modo, pode-se perceber que houve o desenvolvimento da competência do raciocínio crítico por parte dos alunos que participaram das aulas.

Para desenvolver a competência argumentativa na questão 6 , em uma das atividades a turma foi dividida em dois grupos com o intuito de realizar um debate. Cada grupo deveria escolher um dos seguintes temas (aborto, Lei Seca, voto obrigatório). Cada grupo foi dividido em dois subgrupos: um a favor do tema e o outro contra. Por exemplo, o grupo escolheu o tema do aborto, foi dividido em dois: um a favor do aborto e outro contra. Cada subgrupo teve cerca de 10-20 minutos para construir sua argumentação (contra ou a favor do tema), o subgrupo apresentou seus argumentos sem interrupções. Depois da primeira apresentação, os subgrupos contra-argumentaram a 
partir do que o outro subgrupo apresentou. A cada subgrupo será dado o direito de contra-argumentar 2 vezes. Os outros dois subgrupos (com outro tema) votaram naquele que apresentou melhores argumentos/contra-argumentos, justificando a escolha. Outra atividade foi o estudo de falácias através de um seminário, no qual os alunos desenvolveram uma propaganda de um produto e precisavam fazer com que os demais colegas fossem persuadidos a adquirir o produto através de falácias.

A questão 6, dava o comando para responder se é possível acreditar que uma coisa pode ser verdadeira ou falsa ao mesmo tempo.

"Questão 6: É possível acreditar que uma coisa pode ser certa e errada ao mesmo tempo, a exemplo da seguinte frase de Ana? Ana: Eu acho errado, mas eu acho certo eu poder ir agora.

a) Sim.

b) Não.

c) Talvez."

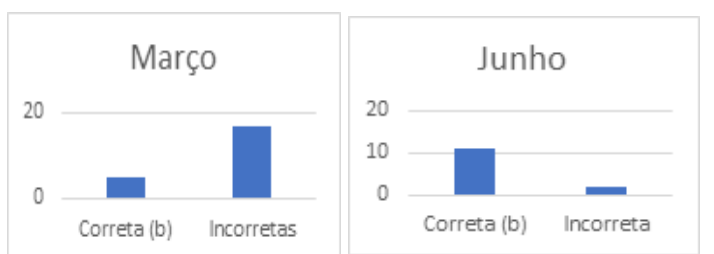

Figura 2: Gráficos das respostas da questão 6 do questionário.

A alternativa correta é a letra 'b', pois acreditar que $\mathrm{P}$ e não $\mathrm{P}$ é contraditório, é inconsistente. Com isso, chega-se ao Princípio da 'Não-contradição' segundo este afirmar e negar ao mesmo tempo um predicado é o mesmo que se contradizer. Assim, quem faz isso, na verdade não está dizendo nada, haja vista que não consegue sustentar sua posição.

Duas proposições contraditoriamente opostas não podem ser simultaneamente verdadeiras, nem simultaneamente falsas. Se uma delas é verdadeira, a outra tem que ser falsa. Pois quem fala com sentido tem que dizer algo determinado, ou seja, tem que afirmar algo como verdadeiro (CIRNE-LIMA, 1993, p. 11).

Nesse gráfico da questão '6', percebe-se que houve alteração nas respostas dos alunos, no gráfico de Março a quantidade de alunos que marcaram as respostas incorretas é bem maior do que aqueles que marcaram a resposta certa. Assim, como no gráfico da primeira questão, os alunos que participaram de todas as atividades e da segunda aplicação do questionário tiveram a chance de marcar a alternativa correta entendendo, porque erraram anteriormente. Deste modo, se percebe que houve o desenvolvimento da competência argumentativa por parte dos alunos que participaram das aulas.

Nesse sentido, com as representações dos avanços dos estudantes através dos gráficos, nota-se a importância de trabalhar com competências desenvolvidas com o ensino da lógica. Além de mostrar que o estágio foi concluído de modo satisfatório tanto para o professor quanto para os alunos, apesar do tempo ter sido curto.

\section{Conclusão}

A partir do Estágio Supervisionado III e dos resultados obtidos conclui-se que o ensino da lógica é indispensável para a formação de cidadãos críticos. Apesar da quanti- 
dade de aulas usufruídas para desenvolver o conteúdo programado terem sido poucas, o retorno dos alunos foi considerado satisfatório para compreender que uma pessoa que possui uma formação cidadã estará apta para solucionar qualquer problema tanto no campo individual, social quanto no político. A lógica é importante para a formação de cidadãos, porque se faz presente nas relações dos humanos com outros e com o mundo que o cerca, uma vez que o humano reflete, analisa, e questiona sobre os acontecimentos que o rodeiam. O aluno deve ter uma formação que desenvolve suas capacidades, não apenas para o meio escolar, mas para todos os âmbitos da vida, por isso, a ideia de trabalhar com competências do ensino da lógica. Deste modo, desenvolver competências coloca em questão a importância dos conhecimentos adquiridos na escola e sua aplicação na realidade para além das exigências estritas para o mercado de trabalho. As competências do raciocínio crítico e da argumentação se mostraram essenciais à vida numa sociedade democrática.

\section{Referências}

BRASIL. Lei $\mathrm{N}^{\circ} 13.415$, de 16 de Fevereiro de 2017. Disponível em: http://www.planalto.gov.br/ccivil_03/_ato2015-2018/2017/lei/L13415.htm. Acesso em: 15 jun. 2017.

BRASIL. Ministério da Educação. Base Nacional Comum Curricular: educação é a base. Disponível em: http://basenacionalcomum.mec.gov.br/images/BNCC_20dez_site.pdf . Acesso em: 28 fev. 2018.

BRASIL. Ministério da Educação. Ciências humanas e suas tecnologias. Brasília: Secretaria de Educação Básica, 2006.

CAMELO, M. N. C. G. A Relevância do Estudo de Lógica para o Ensino Médio. Ceará: REVISTA EROS, 2014.

CIRNE-LIMA, C. Sobre a contradição. Porto Alegre: Edipucrs, 1993.

COPI, I. M. Introdução à lógica. São Paulo: Mestre Jou, 1978.

DALBOSCO, C. A. Educação superior e os desafios da formação para a cidadania democrática. São Paulo: Avaliação: Revista da Avaliação da Educação Superior, v. 20, 2015.

DUTRA, J. S.; FLEURY, M. T. L.; RUAS, R. Competências: Conceitos, métodos e experiências. São Paulo: Atlas S. A, 2008.

FAVARETTO, C. Prefácio da Primeira Edição. In: ROCHA, R. P. Ensino de Filosofia e Currículo. 2. ed. Santa Maria: Ed. UFSM, 2015.

GEACH, P. T. Razão e argumentação. Porto Alegre: Penso 2013.

HECK, R. L. Ensino da lógica na filosofia: filosofia da lógica e pensar crítico. Belo Horizonte: Sapere Aude, v. 8, n. 15, p. 62-85, 2017.

MURCHO, D. A natureza da filosofia e o seu ensino. Lisboa: Plátano, 2002. 
MURCHO, D. O Lugar da Lógica na Filosofia. Lisboa: Plátano, 2003.

NUSSBAUM, M. Sem Fins Lucrativos: Por que a democracia precisa das humanidades. São Paulo: Wmf Martins Fontes, 2015.

ORDINE, N. A utilidade do inútil: um manifesto. Rio de Janeiro: Zahar, 2016.

ROCHA, R. P. Ensino de Filosofia e Currículo. 2. ed. Santa Maria: Ed. UFSM, 2015.

SAJURIA, E. S.; MARTELLET, M. L. B. Rumo a uma renovação educativa hoje: Desafios para o educador. Santa Maria: Pallotti, 1999.

SMULLYAN, R. M. Alice no país dos enigmas. J. Zahar Ed., 2003.

SOFISTE, J. G. Sócrates e o Ensino de Filosofia: Investigação Dialógica: uma pedagogia para a Docência de Filosofia. Petrópolis: Vozes, 2007.

PORTO, L. S. Pensamento crítico e ensino de filosofia. In: REBELLO, J. P.; PORTO, L. S. Iniciação à Docência em Filosofia: Reflexões sobre o ensino, São Leopoldo: Oikos, 2012.

VELASCO, P. D. N. Educando para a argumentação: contribuições do ensino da lógica. Belo Horizonte: Autêntica, 2016.

WALTON, D. N. Lógica informal. São Paulo: Martins Fontes, 2006.

WAGNER, Pierre. A lógica. São Paulo: Parábola, 2009.

ZABALA, A.; ARNAU, L. Como aprender e ensinar competências. Porto Alegre: Artmed, 2010.

Recebido em: 03/08/2019

Aprovado em: 15/10/2020 